\title{
POESIA E MUNDO: TRADUZINDO "UMA EXPEDIÇÃO NÃO REALIZADA AO HIMALAIA" DE WISLAWA SZYMBORSKA
}

\author{
Regina Przybycien
}

\section{Preâmbulo brevíssimo}

Wisława Szymborska e Czesław Miłosz são certamente os poetas poloneses contemporâneos mais traduzidos e conhecidos mundialmente. Ganhadores do prêmio Nobel (Miłosz em 1980 e Szymborska em 1996), ambos representam em suas obras, cada qual a sua maneira, as grandes questões que permearam o século XX. Miłosz, que viveu décadas no exílio, teve grande parte de sua extensa obra publicada em Paris e traduzida para vários idiomas, ao passo que Szymborska passou toda sua vida na Polônia, em sessenta anos publicou escassos doze volumes de poesia e só ficou realmente conhecida fora de seu país após ganhar o Nobel.

Miłosz faleceu em Cracóvia em 2004 e está sepultado numa cripta junto a outros grandes poetas do passado na igreja de Santo Estanislau sobre o Rochedo. Szymborska, que em 2011 completa 88 anos, continua vivendo uma vida discreta em Cracóvia, para onde se mudou ainda menina. Pouco afeita às viagens e badalações, tenta se preservar do inevitável assédio da mídia, de críticos e admiradores, depois que se tornou uma personalidade famosa no mundo literário.

Em seu discurso por ocasião do recebimento do prêmio Nobel em 1996, Szymborska afirmou que valoriza acima de tudo esta frase: "não sei". Para ela somente esta admissão de ignorância pode expandir os horizontes - tanto interiores quanto exteriores. Pela inquietude de não saber, o cientista busca, investiga e descobre novas leis. Com cada criação o poeta tenta responder a esse desconhecimento, mas se dá conta de que a resposta é sempre insuficiente e tenta de novo e de novo; a essas tentativas frustradas os historiadores da literatura vão chamar de sua "obra”. (Szymborska, 2010: 407). A obra de Szymborska é uma inquirição constante do mundo numa poesia que a maioria dos críticos concorda em chamar de simples e direta. Sobre essa simplicidade, Clare Cavanaugh (2003: 10) afirma: "O talento excepcional de Szymborska se mostra na capacidade de dar visibilidade ao extraordinário no aparente mundo ordinário à nossa volta." Essa sensação de proximidade com o mundo que sua poesia provoca, a 
abordagem de questões filosóficas em imagens concretas e linguagem acessível lhe trouxe um grande número de admiradores em todo o mundo.

Stanisław Balbus (1996:10) atribui o fenômeno à capacidade de sua poesia de "exprimir o máximo das questões de peso que perpassam a vida espiritual do mundo contemporâneo em um número mínimo de textos poéticos". O crítico lembra que a visão do mundo da poeta se estende a um vasto campo de interesses. Sua indagação se dirige a um grão de areia ou uma pedra, à vida das plantas e à evolução das espécies, à história humana e ao surgimento de planetas, estrelas, galáxias.

$\mathrm{Na}$ cosmovisão de Szymborska, o homem, embora represente o ápice da evolução, não ocupa o centro. É visto em relação com outras formas de vida ou como frágil caniço pensante equilibrando-se precariamente num pequeno e frágil planeta. É uma visão sombria, permeada de ceticismo filosófico e grande dose de ironia, mas mitigada pelo humor que perpassa quase toda a sua produção. Em seus poemas não falta empatia, mas o humor e a ironia criam um distanciamento do eu lírico e evitam que caia no trágico ou no patético.

\section{De uma expedição não realizada ao Himalaia}

Para ilustrar a poética de Szymborska escolhi um poema da coletânea Wolanie do Yeti (Chamando pelo Yeti) de 1957, por julgar que ele apresenta características que se tornarão a marca registrada da poeta em sua produção posterior. Segundo Balbus (1996:12) neste livro aparece pela primeira vez a questão do "ser-outro", uma outridade que se estende para além do mundo humano e que, para Szymborska, tem sua própria realidade, distinta da nossa, impenetrável para nós e independente do nosso olhar. Em poemas posteriores, o eu lírico especula como é o ser (a essência) da pedra, do grão de areia, da cebola ou como seria o seu ser se tivesse surgido em outra forma, não humana: se ao invés de pele, tivesse escamas ou casca ou se ao invés de caminhar rastejasse. Enfim, é uma poesia que indaga sempre, que se compraz em indagar não somente "por quê", mas sobretudo "e se ..." abrindo-se para a multiplicidade do ser no mundo.

Na coletânea Wołanie do Yeti é Yeti, este ser lendário, que representa a outridade a que a poeta se dirige no poema "Z nieodbytej wyprawy w Himalaje".

Eis o poema com a minha tradução: 
Z nieodbytej wyprawy w Himalaje

Aha, więc to są Himalaje. Góry w biegu na księżyc. Chwila startu utrwalona na rozprutym nagle niebie. Pustynia chmur przebita. Uderzenie w nic.

Echo - biała niemowa.

Cisza.

Yeti, niżej jest środa, abecadło, chleb i dwa a dwa to cztery i topnieje śnieg. Jest czerwone jabłuszko przekrojone na krzyż.

Yeti, nie tylko zbrodnie są u nas możliwe. Yeti, nie wszystkie słowa skazują na śmierć.

Dziedziczymy nadzieję dar zapominania. Zobaczysz jak rodzimy dzieci na ruinach.

Yeti, Szekspira mamy. Yeti, na skrzypcach gramy. Yeti, o zmroku zapalamy światlo.

$\mathrm{Tu}$ — ni księżyc, ni ziemia i łzy zamarzają. O Yeti Półtwardowski, zastanów się, wróć!

Tak w czterech ścianach lawin wołałam do Yeti przytupując dla rozgrzewki na śniegu na wiecznym.
De uma expedição não realizada ao Himalaia

Ah, então este é o Himalaia.

Montanhas correndo para a lua.

$\mathrm{O}$ instante da largada fixado

no rasgar súbito do céu.

Deserto de nuvens perfurado.

Um golpe no nada.

Eco - uma branca mudez.

Silêncio.

Yeti, lá embaixo é quarta-feira

tem abecedário, pão

dois e dois são quatro

e a neve derrete.

Tem rosa amarela,

tão formosa, tão bela.

Yeti, nem só crimes acontecem entre nós.

Yeti, nem todas as palavras condenam à morte.

Herdamos a esperança -

o dom de esquecer.

Você vai ver como damos

à luz em meio a ruínas.

Yeti, temos Shakespeare lá, Yeti, e violinos para tocar.

Yeti, ao cair da noite acendemos a luz.

Aqui - nem lua nem terra e a lágrima congela.

Ó Yeti meiolunar

pense, volte!

Entre as quatro paredes da avalanche assim eu chamava pelo Yeti batendo os pés para me aquecer na neve

na eterna. 
Comentando este poema, Tadeusz Nyczek (2005) recorda o contexto cultural dos anos 1950 na Polônia. Com a relativa distensão política após a morte de Stalin (embora ainda existisse a censura), pela primeira vez desde antes da Segunda Guerra os intelectuais puderam ter contato com as artes ocidentais e ter liberdade para criar formas artísticas não atreladas à ideologia oficial. Nyczek menciona alguns acontecimentos culturais que permaneceram na memória dos poloneses, como o Festival Internacional da Juventude em Varsóvia em 1955, que reuniu jovens do mundo inteiro: um espetáculo inusitado para quem saía do fechado e sombrio regime stalinista. Mas a época foi marcante sobretudo pelas várias atividades artísticas: apareceram grupos de teatro experimental, com criadores que se notabilizaram internacionalmente como Kantor e Grotowski; o cinema polonês viveu um momento de grande criatividade com os diretores oriundos da Escola de Łodź (Munk, Wajda, Polański e vários outros) e os escritores puderam finalmente expressar uma voz individual, como foi o caso de Szymborska com a coletânea Wołanie do Yeti.

O título do livro remete ao lendário Yeti, o abominável homem das neves das montanhas geladas do Himalaia. Para os habitantes das aldeias vizinhas, o personagem é real e cada um afirma tê-lo visto em algum momento. Seus relatos alimentaram a lenda e fizeram com que a partir de meados do século XIX várias expedições ocidentais saíssem em busca do humanoide. Como prova de sua existência, apresentaram fotos de grandes pegadas na neve. Yeti, tímido e arredio, nunca foi visto, pois (diz-se) foge dos humanos.

Em 1953 os alpinistas Tensing e Hillary realizaram a primeira escalada bem sucedida ao topo do Monte Everest. O fato teve larga cobertura na imprensa internacional e pode ter sido uma fonte de inspiração para o título do livro de Szymborska e para o poema aqui reproduzido. Como o título do poema é "De uma expedição não realizada ao Himalaia”, fica a impressão de que o eu lírico contempla uma foto das montanhas ou as imagens de um cine jornal ou documentário.

A primeira estrofe do poema põe em marcha uma série de metáforas de movimento para caracterizar o Himalaia como uma espécie de precipitação abrupta rumo ao céu. A estrofe termina com a combinação de um oximoro e uma sinestesia: "Eco - uma branca mudez", seguida da palavra silêncio. O conjunto de metáforas sugere força, imponência, inacessibilidade e ausência de vida. 
As estrofes seguintes são um apelo a Yeti para que desça da montanha. A enumeração das razões para convencê-lo de que vale a pena são bem características do estilo de Szymborska. Cá embaixo temos o tempo ("é quarta-feira"), a cultura (o abecedário, Shakespeare, música) a ciência (“dois e dois são quatro"). Mas há uma nota sombria expressa na terceira estrofe: "nem só crimes/ acontecem entre nós./ Nem todas as palavras condenam à morte.” A negação implica que nem tudo são conquistas nessa civilização: há crimes e morte dos quais, de alguma maneira, a humanidade sempre se recupera, pois temos o dom do esquecimento e da esperança e a capacidade de renovação: "damos/ à luz em meio a ruínas". O chamado pelo Yeti não é um desejo de alcançá-lo nas alturas, mas um apelo para que desça e habite entre os humanos. As razões do eu lírico sugerem que, apesar de tudo, a vida cá embaixo é digna de ser vivida, pois a alternativa é o vazio, "branca mudez”, neve eterna. O nada. Em outros termos, Yeti representa tudo que é misterioso, elevado, inatingível: pura poesia. Mas no mundo humano nada é puro, nem mesmo a poesia.

\section{Traduzindo Szymborska}

A linguagem da poeta, embora simples, constitui um desafio para os tradutores. Em primeiro lugar, há a questão de encontrar o tom adequado para representar em outro código linguístico o coloquialismo dessa poesia. Em segundo lugar, Szymborska tira do repertório erudito e popular da língua e da cultura polonesa (e reelabora para uso próprio) grande quantidade de referências: provérbios, adágios, trechos de canções que o leitor polonês reconhece facilmente, mas que não fazem sentido para um leitor estrangeiro.

O poema aqui analisado é relativamente simples e não apresenta grandes dificuldades à tradução. Mesmo assim, há várias questões que o tradutor tem que considerar. Quanto ao coloquialismo, por exemplo, o uso do pronome "tu" indica grande informalidade na língua polonesa e é utilizado somente para pessoas muito próximas ou para crianças, mas no Brasil a sua utilização na escrita é uma estilização literária. O uso de "você", nosso tratamento informal, tem a desvantagem de tornar o verso mais longo. Assim, enquanto o polonês utiliza apenas uma palavra "zobaczysz" (“verás"), o português brasileiro necessita de três: "você vai ver", para expressar essa informalidade. Procurei manter a mesma extensão dos versos do original, o que nem sempre foi possível porque, como todas as línguas eslavas, o polonês não possui artigos 
e é altamente flexionado. Isso dá maior concisão aos versos, como se pode verificar visualmente no poema mesmo sem entendê-lo.

Outras adaptações têm a ver com o léxico. No penúltimo verso da primeira estrofe: "Echo — biała niemowa" a expressão "biała niemowa" significa "mudo branco" ("mudo" no sentido de uma pessoa que não fala ou, figurativamente, pessoa muito calada, que quase não fala). Pareceu-me que o verso em português: "Eco - um mudo branco" não funciona, portanto ao invés de "mudo", utilizei "mudez", "uma branca mudez", mais poético, tendo porém a desvantagem de elevar demasiado o tom, principalmente pela inversão do adjetivo, necessária para evitar uma certa cacofonia em "uma mudez branca".

No poema Szymborska faz duas apropriações do repertório da cultura popular de seu país. Os dois últimos versos da segunda estrofe, “czerwone jabłuszko/ przekrojone na krzyż" (literalmente: "uma maçãzinha vermelha/ cortada em cruz") são os versos iniciais de uma das mais conhecidas cantigas folclóricas polonesas, na qual um rapaz e uma moça flertam de forma brejeira. A canção é ingênua, infantil. Uma tradução literal ou aproximada não faz sentido, já que se perdem as referências. Busquei então nas cantigas de roda algo que pudesse soar bem sem fugir inteiramente do contexto. Pareceu-me que a canção "Rosa amarela" cujos primeiros versos são: "Olha a Rosa amarela/Rosa tão formosa, tão bela, Rosa” preenchia de certa forma as características que eu buscava, com a vantagem de me fornecer uma boa rima.

Outra adaptação, mais difícil, diz respeito ao terceiro verso da penúltima estrofe, "O Yeti Półtwardowski”, no qual Szymborska alude a uma personagem muito conhecida do folclore da Polônia. Segundo as informações de Tadeusz Nyczek (2005: 52) Pan Twardowski (o Senhor Twardowski) é um Fausto polonês cuja lenda tem origem no século dezesseis. Um mago aristocrata que vendeu a sua alma e acabou sendo sequestrado pelo diabo e levado até a lua, onde mora até hoje. Szymborska chama Yeti de "Póltwardowski". "Poł" significa "meio" em polonês, portanto Yeti seria um "Meio Twardowski” - novamente uma referência que se perde totalmente para o leitor estrangeiro. A ligação que Nyczek faz entre as duas personagens faz sentido: Pan Twardowski é um habitante da lua, Yeti, do Himalaia, essas montanhas quase tão inacessíveis quanto a lua, portanto Yeti, morador misterioso dos píncaros das montanhas é “meio Twardowski”. Traduzi-o, portanto, como meiolunar.

A título de comparação, vejamos as soluções dos tradutores para o inglês e para o espanhol dos dois casos acima mencionados. Na versão de Barańczak e Cavanaugh 
(1998:18) a "maçãzinha vermelha/ cortada em cruz" virou "Roses are red there/ and violets are blue", versos conhecidíssimos na língua inglesa e, portanto, uma equivalência interessante da canção polonesa. O verso "O Yeti - Półtwardowski” virou “Oh Yeti - semi-moonman." A repetição do "m” e “n” cria aliterações não existentes no polonês mas "moonman" funciona muito bem. Na versão espanhola temos: "Hay uma manzana roja/ partida en cuatro" e "Oh, Yeti, casi hombre de la luna". No primeiro caso a versão literal não faz sentido em espanhol e no segundo, o tradutor alongou demasiado o verso (sete palavras no lugar das três em polonês), quebrando o ritmo ágil do poema.

Podemos verificar que mesmo um poema simples como este exige que o tradutor faça escolhas difíceis. Os tradutores para a língua inglesa, Clare Cavanaugh e Stanisław Barańczak, trabalham muito bem juntos. Cavanaugh é falante nativa do inglês e professora de línguas eslavas e Barańczak é um poeta muito respeitado. Como os irmãos Campos, Barańczak realiza transcriações dos poemas de Szymborska de forma muito criativa, às vezes com soluções geniais, mas alguns críticos observam que os poemas em inglês se parecem mais com Barańczak do que com Szymborska. Talvez isso seja inevitável se quisermos uma tradução realmente poética.

Eu não sou poeta. Minhas traduções resultam de uma forte identificação com a poesia de Szymborska e de um desejo de torná-la mais conhecida no Brasil. Procurei respeitar, tanto quanto possível, o tom e o sentido dessa poesia. O resultado muitas vezes é insatisfatório, mas deu-me prazer tentar.

\section{Referências bibliográficas}

BALBUS, S. (1996) Słowo wstępne - Tak mało wierszy, tak wiele poezji. In: BALBUS, S., WOJDA, D. (Org.). Radość czytania Szymborskiej — Wybór tekstów krytycznych. Kraków: Wydawnictwo Znak, p.7-19.

CAVANAUGH, C. (2003) Przekształcanie zwyczajności: o przekładaniu Wisławy Szymborskiej. Tradução Magda Heydel. Przekładaniec, n. 10, 1, p. 10-19.

NYCZEK, T. (2005) Tyle naraz świata - 27 x Szymborska. Kraków: Wydawnictwo a5, $307 \mathrm{p}$.

SZYMBORSKA, W. (2010) Wiersze wybrane. Kraków: Wydawnictwo a5, 433p.

(1998) Poems new and collected 1957-1997. Tradução Stanisław Barańczak e Clare Cavanaugh. New York: Harvest Book, 273 p. 
(2005) Paisaje con grano de arena. Tradução Ana María Moix e Jerzy Wojciech Sławomirski. Barcelona: Lumen, 216p. Título original: Widow z ziarnkiem piasku. 